\title{
Comparative Chemical Analyses of Vernonia amygdalina and Azadirachta indica Leaves
}

\author{
C.E. Offor \\ Department of Biochemistry, Ebonyi State University, Abakaliki, Nigeria
}

\begin{abstract}
The chemical and elemental constituents of Vernonia amygdalina and Azadirachta indica leaves were investigated. Phytochemical analysis was determined by the methods of Association of Analytical Chemists $(A O A C)$. The trace elements and macronutrients concentrations of both samples were determined using Atomic Absorption Spectrometer $(A A S)$. Vernonia amygdalina leaves recorded significantly $(p<0.05)$ higher levels of flavonoids, saponins and caroteinoids while Azadirachta indica leaves had higher levels of alkaloids, glycosides, phenols and steroids. Vernonia amygdalina also recorded higher concentrations of zinc, iron, and manganese while there were higher levels of nickel, molybdenum, cobalt, silicon and lead in the leaves of Azadirachta indica. There were higher levels $(\mathrm{mg} / \mathrm{l} 00 \mathrm{~g})$ of potassium, sodium and phosphorus in Azadirachta indica which recorded $0.843 \pm 0.019,0.301 \pm 0.047$ and $0.280 \pm 0.002$ respectively with corresponding values in Vernonia amygdalina as $0.710 \pm 0.016,0.334 \pm 0.006$ and $0.382 \pm 0.006$. The results showed that both leaves contained varying concentrations of chemical, elemental and macronutrient components. They can serve as good sources of useful elements. The leaves of Vernonia amygdalina could have better anti-oxidant properties than Azadirachta indica leaves.
\end{abstract}

Key words: Chemical analysis, Vernonia amygdalina, Azadirachta indica.

\section{Introduction}

Plants have been used both by traditional herbalists and pharmacists for synthetic preparations in the pharmaceutical industries and for management and treatment of different diseases that affect man [1]. The knowledge of medicinal plants has continued to be useful in the production of drugs, food, spice, perfume and preparation of surgical dressings [2]. The retention of medicinal practices and traditions is evident mainly in the rural communities. With modern technology, medicine has moved from a purely traditional phase to high technological production of synthetic chemicals and the extraction of chemicals from plants to produce drugs. Several of these drugs are derived from plants that form the basis of traditional medicine [3].

Therefore, medicinal plants are plants that contain medicinal products as their active ingredients. Medicinal plants are used commercially in modern medicine and pharmacology [4]. The standardization of Nigerian medicinal plants has long been on-going in Nigeria in the attempt to set appropriate pharmacopoeia standards and obtain the quality of plants in our natural environment [5]. Plants used as natural medicine are seen to be in three ways. Firstly, they may be used directly as tea or in other extracted forms for their natural chemical constituents. Secondly, they may be used as agents in the synthesis of drugs. Finally, the organic molecules found in plants may be used as models for synthetic drugs [6].

The research of plants' bioactive substances has contributed immensely for the betterment of mankind through the provision of value added economic returns, manufacturing of natural plant production industry, provision of better health care and increase in export earning in both rural and urban areas [7]. Vegetables, especially leaves, are important sources of vitamins, minerals, fiber, and some essential amino acids [8]. Vegetables when eaten in sufficient amounts may be helpful in reducing the incidence of colon and stomach cancers [9]. For continued consumption of vegetable and derivation of the immense nutritional benefits they offer, especially to the low income group who cannot afford the more expensive alternative sources, ways and means have to be sought to eliminate or at least reduce significantly the potential toxicological dangers of the constituent anti-nutrients and toxic substances [10]. This could be by the manipulation of one of the following: the soil environment in which the plant is grown, time or season of planting, and/or harvesting, type of species grown, and preservation and processing methods [11]. Therefore, our current knowledge of the practical means by which the levels of these substances could be reduced to within safe limits of $0.05 \%$ is grossly inadequate. Unfortunately, these substances are inevitably present in vegetables. This limits the importance of vegetables in the nutrient, as the nutritional importance of any given food is a function of its nutrient and anti-nutrient composition [12].

Anthropologists theorized that animals evolved a tendency to seek out bitter plant in response to illness. This behaviour arose because bitterness is an indicator of secondary metabolites. Tradomedicine is, in fact, as old as creation [13]. Hence, mankind has used plant extracts for thousands of years for the prevention of diseases, treatment of disease symptoms, as insecticides to control microbial growth, for weed control and many 
more functions. Many of these activities are due to the presence of highly diverse secondary metabolites called phytochemicals produced by plants as defense mechanism against predation by microorganisms, insects and herbivores [14].

Azadirachta indica (neem) is a tree in the mahogany family. It is one of the species in the genus "Azadirachta" and is native to India, Bangladesh and Pakistan, growing in tropical and semi-tropical regions. Other names include "dogonyaro", "vimba" and "kohomba". In East Africa, it is also known as "muarubaini" which means the tree of the 40 , as it is said to treat 40 different diseases [15]. It is an evergreen tree, cultivated in various parts of the world. Every part of the tree has been used as traditional medicine for house hold remedy against various human ailments from antiquity [16]. Neem has been extensively used in ayurveda and homoeopathic medicine and has become a cynosure of modern medicine. The importance of the neem tree has been recognized by the US National Academy of Sciences, which published a report in 1992 entitled "Neem - a tree for solving global problems". The advancement of neem research has been documented [17].

Vernonia amygdalina (bitter leaf) is one of the widely studied medicinal plants. It belongs to the family "compositae". It occurs as a small shrub with height from $2-5 \mathrm{~m}$, the stem is rough with young branches and petiolate green leaves of about $6 \mathrm{~mm}$ diameter. The leaves are elliptic in shape, short acuminate at the apex and slight chordate at the base. The bitter taste of the plant leaves gives rise to its common name "Bitter Leaf" [18]. The bitterness can be abated by boiling or soaking in several changes of clean water [19].

Furthermore, various studies have been reported on the safety evaluation of neem and bitter leaves. Methanol extract of neem leaves exhibits oral toxicity in mice. Crude neem leaf-extract causes structural change in meiotic chromosomes, decrease in sperm count and sperm motility. Saponins extracted from these plants are toxic when they have direct contact with systemic circulation [20]. In view of the above - mentioned facts, there is a need to conduct chemical studies on both Vernonia amygdalina and Azadirachta indica leaves to elucidate their comparative chemical properties. This work was aimed at investigating the comparative phytochemical analyses on the leaves of Azadirachta indica and Vernonia amygdalina and to estimate the concentrations of their trace elements and macronutrient status.

\section{MATERIALS}

\section{Materials And Methods}

Fresh leaves of Vernonia amygdalina and Azadirachta indica were collected from Abakaliki in Ebonyi State. Sixteen male albino rats were obtained from Zoology Department, University of Nigeria, Nsukka, Nigeria. All the chemicals and reagents used were of analytical standard.

\section{METHODS}

\section{Chemical Analyses}

(a) The method of Onwuka [21] was adopted to assay the quantitative phytochemical analyses to determine the concentrations of alkaloids, flavonoids, glycosides, saponins, tannins, phenols, $\beta$-carotenoids, cyanogenic glycosides and steroids in the leaves of Azadirachta indica and Vernonia amygdalina.

(b) Concentration of trace elements (copper, zinc, iron, manganese, nickel, molybdenum, cobalt, silicon and lead) and macronutrients content (sodium, potassium, calcium, phosphorus and magnesium) in Azadirachta indica and Vernonia amygdalina leaves were determined using atomic absorption spectrometer (AAS).

\section{Data Analysis}

All the tested parameters were subjected to statistical analysis using t-test. Differences between means were regarded significant at $\mathrm{p}<0.05[22]$.

\section{Results And Discussion}

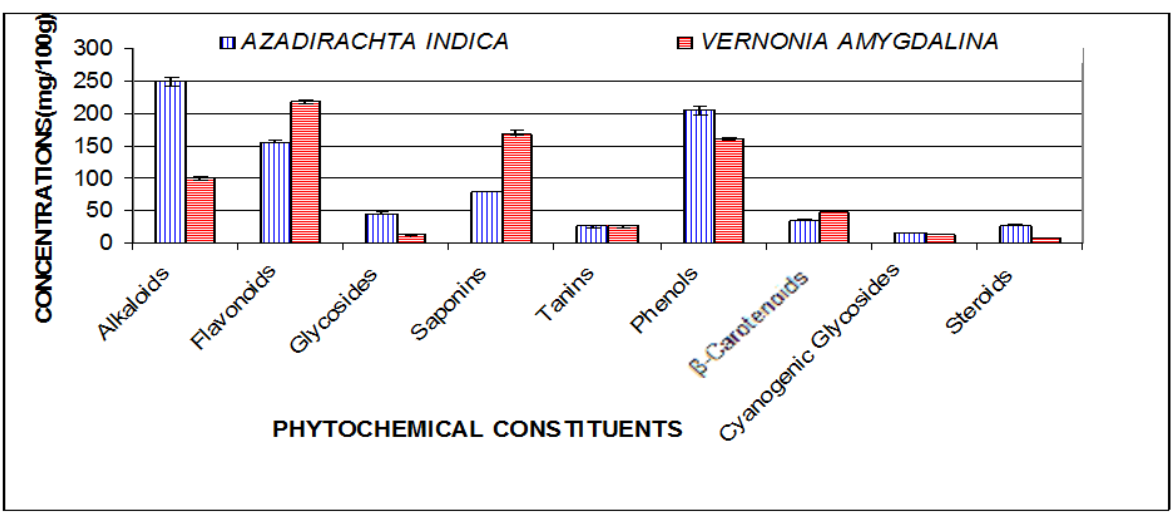


Fig.1: Phytochemical Composition of Dry Azadirachta indica and Vernonia amygdalina Leaves. The leaves of both plants contained varying concentrations of phytochemical components.

Table 1: Concentrations (mg/100g) of Trace Elements in Azadirachta indica and Vernonia amygdalina Leaves ELEMENTS

\begin{tabular}{lcc}
\hline Trace Elements & Azadirachta indica & Vernonia amygdalina \\
\hline Copper $(\mathrm{Cu})$ & $0.320 \pm 0.009$ & $0.120 \pm 0.006$ \\
Zinc $(\mathrm{Zn})^{*}$ & $0.716 \pm 0.005$ & $0.812 \pm 0.006$ \\
Iron $(\mathrm{Fe})^{*}$ & $1.667 \pm 0.047$ & $1.758 \pm 0.024$ \\
Manganese $(\mathrm{Mn})^{*}$ & $0.230 \pm 0.041$ & $0.261 \pm 0.006$ \\
Nickel $(\mathrm{Ni})$ & $0.091 \pm 0.013$ & $0.066 \pm 0.008$ \\
Molybdenum(Mo) & $0.011 \pm 0.004$ & $0.007 \pm 0.001$ \\
Cobalt $(\mathrm{Co})$ & $0.019 \pm 0.003$ & $0.010 \pm 0.004$ \\
Silicon $(\mathrm{Si})$ & $0.006 \pm 0.001$ & $0.004 \pm 0.001$ \\
Lead $(\mathrm{Pb})$ & $0.020 \pm 0.000$ & $0.010 \pm 0.001$ \\
\hline
\end{tabular}

*These elements were higher in the leaves of Vernonia amygdalina while others were higher in Azadirachta indica.

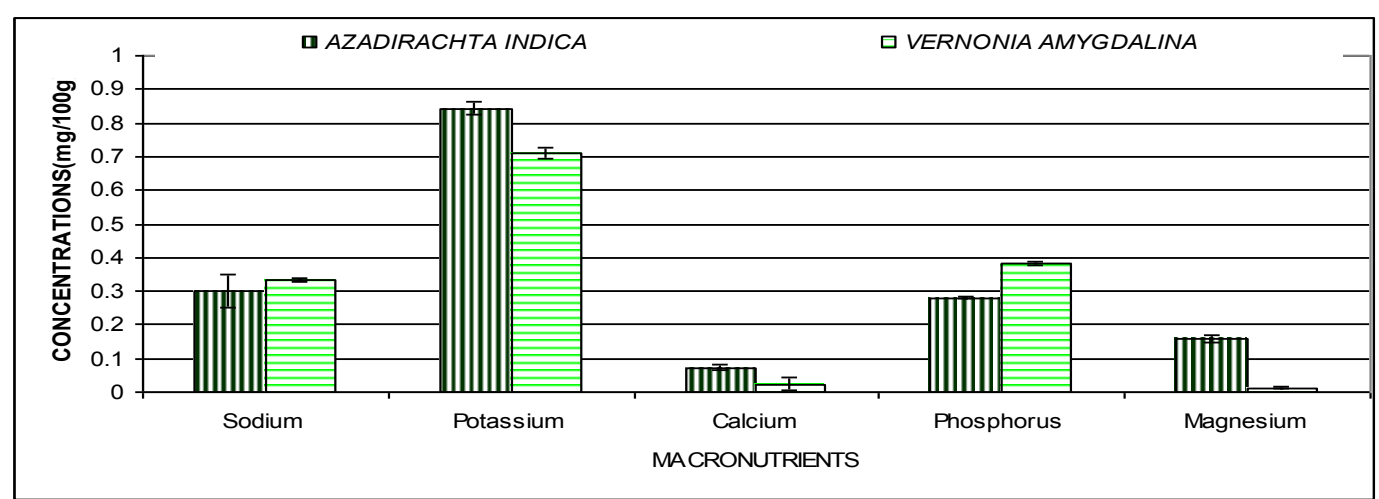

Fig.2: Macronutrient Content of Azadirachta indica and Vernonia amygdalina Leaves. Both samples contained significant amounts of sodium, potassium, and phosphorus. The leaves of Vernonia amygdalina recorded higher amounts of phosphorus and sodium only.

Phytochemical analyses of Vernonia amygdalina and Azadirachta indica leaves showed that both plants contained relatively high levels of alkaloids, flavonoids and phenols and minimal concentrations of other phytochemicals (Fig. 1). Most medicinal plants are often rich in alkaloids and this can be physically observed by their stiff nature [23]. Azadirachta indica is rich in flavonoids [24]. The quantitative phytochemical analysis of Vernonia amygdalina leaves recorded higher levels of flavonoids, saponins and $\beta$-caroteinoids while Azadirachta indica recorded higher levels of alkaloids, glycosides, phenols and steroids (Fig. 1). This is because of the differences in species variation [24]. Strong antioxidant activities have been reported for flavonoids from Vernonia amygdalina and its saponins have been reported to elicit antitumoral activities in leukemia cells [25]. Phytochemical analysis of Vernonia amygdalina leaves showed that anthracene, glycosides, steroids, flavonoids, proteins, carbohydrates, reducing sugars, saponins and tannins were present [26]. Phytochemical screening of Vernonia amygdalina revealed the presence of saponins, sesquiterpenes and flavonoids [27]. Tannins are relatively present in the sesame plant and chick weed [28]. Zingiber officinale, Viscum album and Azadirachta indica are also rich in tannins [29].

The samples also had high concentrations of phenols and glycosides. Phenols are moderately present in Telfairia occidentalis [23]. They are also moderately present in Mucuna pruriens and the inhibition of ATPase activity in Vernonia amygdalina is due to high concentration of glycosides which regulate the sodium/potassium ion pump [30].

The phytochemical analysis of Azadirachta indica revealed higher concentrations (mg/100g) of alkaloids, glycosides, phenols, steroids and minimal levels of other phytochemicals (Fig. 1). Phytochemical analysis of Aloe socotrina (aloe vera) yielded high levels of steroids, phenols and tannins [31]. Phytochemical analysis of Zingiber officinale (ginger) yielded very high level of phenols [32]. Physalis angulata contains high concentration of tannins, followed by flavonoids, alkaloids and phenols [33]. From the above observations, it is obvious that plants have varying quantities of phytochemical constituents and the plants under study are not exceptions. 
Trace elements analyses showed that both leaves of Vernonia amygdalina and Azadirachta indica contained high levels of iron, zinc, copper, and manganese. Vernonia amygdalina had higher levels of zinc, iron and manganese while higher levels of copper, nickel, molybdenum, cobalt, silicon and lead were found in Azadirachta indica. The concentrations of silicon in Vernonia amygdalina and Azadirachta indica leaves were the lowest (Table 1). This may be because silicon forms complexes with soil and not readily available for plants. Lower levels of cobalt and lead may reflect the non-occurrence of cobalamin (a cobalt porphyrin) [34] and nonnutritive nature of lead in plants [35]. The higher level of iron in Vernonia amygdalina may be traced to the heap of corroded empty food cans usually dumped in the area by its residents. Generally, iron is the highest occurring metal on earth [36].

Macronutrients analysis showed that both samples contained high levels of potassium, phosphorus and sodium. Vernonia amygdalina leaves contained higher levels of sodium and phosphorus while Azadirachta indica leaves had higher levels of potassium, calcium and magnesium. The concentrations of potassium and calcium appeared highest and least respectively in Azadirachta indica leaves (Fig. 2). Azadirachta indica is known to accumulate high level of potash [37].

\section{Conclusion}

The leaves of Azadirachta indica and Vernonia amygdalina contained varying concentrations of chemical, elemental and macronutrient components. They can serve as good sources of useful elements and bioactive compounds. The leaves of Vernonia amygdalina could have better anti-oxidant properties than Azadirachta indica leaves.

\section{References}

[1]. WHO (1998). Regional seminar on intellectual property issues in the field of traditional medicines, New Delhi. 7-10.

[2]. Abayomi, L.K. (1993). Effect of medicinal plants on the blood. Journal of Traditional Medicines, 13: 548-555.

[3]. Bergman, K. N. (2000) Regulation of cholesterol biosynthesis, Journal of Cholesterolemia, 3: 220-224.

[4]. Andrews, D.S. and Fatt, C. (2002). The typical evergreen plant of India "Dogonyaro".Journal of Biological Science, 61: 34 - 40.

[5]. Burkit, D.P. (2003). Neem as a source of treatment to many kinds of diseases. Harvard University press, Cambridge, MassaChusetts. 57-60.

[6]. Roja, G. and Mike, P. S. (2000). Anticancer compounds from tissue cultures of medical plant. Journal of Herbs, Spices and Plants, 7: $71-102$

[7]. Tona, L. (2002). Antiamoebic and spamolytic activities of extracts from some antidiarhoeal traditional preparation used in Kinshasa, Congo. Journal of African Plant, 7: $31-38$.

[8]. Oyenuga, V.A.and Fetuga, B.L. (2003). Medical nutrient. Dietary importance of vegetables. $5^{\text {th }}$ edition, Ibadan press, Nigeria. 122 -129 .

[9]. Whitney, E.N. and Hamilton, E.M. (1990). Vegetables, understanding nutrition. $5^{\text {th }}$ edition, St. Paul, U.S.A. 43.

[10]. Guthrie, H.A. (1990). Nutrition. Introductory nutrition. $5^{\text {th }}$ edition, C.V. Mosby company, London. $19-20$.

[11]. Beentje, H.J. (2000). Flora of Tropical East Africa, Compositae. A.A. Balkema, Rotterdam New York. $1-13$.

[12]. Prohp, T.P., Ihimire, I.G., Madusha, A.O., Okpala, H.O., Eresor, J.O. and Oyinbo, C.A. (2006). Some antinutritional and mineral contents of extra-cotyledons. Pakistan Journal of Nutrition, 5: $114-116$.

[13]. Emeruwa, A. C. (2005). Antibactrial substance from Carica papaya fruit extract. Journal of Pharmacology, 45: 123-127.

[14]. Simon, F. K., Kinsley, M. P. and John, L. P., (2001). Plant metabolites. $6^{\text {th }}$ edition. Hossana press, Nsukka. $180-200$.

[15]. Ganguli, S. (2003). Neem: A therapeutic for all season. Journal of Current Science Leaves and Flowers, 11: 4 - 11.

[16]. Koul, O., Isman, M.B and Ketkar, C.M. (1990). Traditional medicine for household remedy. Canadian Journal of Botany, 68: 1 11.

[17]. Schmutterer, H. (1995). The neem tree: Source of unique natural products for integrated pest management, medicine, industry a nd other purposes. VCH, Weinheim, Germany. $508-696$.

[18]. Nwobegu, J. S. and Egbuna P. A. C., (2002). Antihepatotoxicity of crude extract of Vernonia amygdalina on rat's liver. Research work submitted to the Department of Biochemistry, University of Nigeria, Nsukka. 3-15.

[19]. Mbinglo, S.B. (1998). Survey on the production of bitter leaf. Journal of National Resource Institute, 6: $58-66$.

[20]. George, A.J. (1965). Legal status and toxicity of saponins. Food Cosmetology and Toxicology, 3: $85-91$.

[21]. Onwuka, G.I. (2008). Phytochemical analysis and instrumentation, theory and practices. $2^{\text {nd }}$ edition, Oxford, London. 64-139.

[22]. Oyeka, C.A. (1996). An introduction to applied statistical methods. $7^{\text {th }}$ edition, Nobern Avocation publishing company, Enugu, Nigeria. 189-203.

[23]. Iwu, M. M. (1993). Hand book of African Medicinal Plants. $3^{\text {rd }}$ edition, CRK Press incorporated, Florida. $255-257$.

[24]. Dean, G.S. (2002). Physiological significance of flavonol glycoside. Journal of Biological Science, 30: 24 -29.

[25]. Jisaka, M., Ohigashi, H. and Takagawa, K. (1993). Steroid glucosides from Vernonia amygdalina. A possible chimpanzee medicinal plant. Phytochemistry, 34: 409-413.

[26]. Ojiako, O. A, and Nwanjo, H.V (2006). Is Vernonia amygdalina, hepatotoxic or hepatoprotective?. Response from biochemical and toxicity studies in rats. Journal of African Biotechnology, 5: 1648-1659.

[27]. Igile, G.O., Oleszek, W. and Jurzysta, M. (1994). Flavonoids from Vernonia amygdalina and their antioxidant activities. Journal of Agriculture, Food and Chemistry, 42: 2445-2448.

[28]. Heftman, N.K. (1997). Biochemical significance of some nutrients found in some medicinal plants. Journal of Biochemical Science, 5: $10-20$

[29]. Sofowora, E. A. (2004). Medicinal plant in Africa. $2^{\text {nd }}$ edition, John Wiley and Sons Ltd, New York. 54.

[30]. Coursely, L. (1998). The roles of glycoside in plants. Journal of Pharmacology, 29: $234-236$.

[31]. Drenick, E.T. (2004). Effect of carbohydrate intake in fatty acids break-down. Journal of Science, 202: 1-18.

[32]. Chopra, R.N., (2005). Indigenous drugs of India. Journal of Science, 26; 51-59.

[33]. Aganu, J.C. (2005). An introduction of Gastroenterology. $3^{\text {rd }}$ edition, Heinemann, London. 45-55.

[34]. Ezilo, G.C. (2002). A textbook of physiology. Oxford University press, New Delhi, India. 68-333. 
[35]. Calvary, T.M. (1970). The chemistry of minerals, $2^{\text {nd }}$ Edition, Vision International, Lagos. 61-63.

[36]. Okoli, E.C., Afiukwa, J.N., Chukwu, G.N.O., Obeta, A.E., Nmezi, P.N.A. and Idah, N.N. (2001). Foundation chemistry, $1^{\text {st }}$ edition, Mekand publications, Enugu, Nigeria. 190-208.

[37]. Yumah, C.S. (1991). Tropical botany. $6^{\text {th }}$ edition, Ahmed industries, Zaria. 500-725. 